\title{
An Investigation on Tube Temperature Distribution in a Water Tube Boiler
}

\author{
Shaji kumar K.R ${ }^{1}$,Tide P.S ${ }^{2}$ \\ ${ }^{I}$ Post-graduate Student in Mechanical Engineering, School of Engineering, CUSAT, Cochin, India. \\ ${ }^{2}$ Associate Professor in Mechanical Engineering, School of Engineering, CUSAT, Cochin, India.
}

\begin{abstract}
Thermal power stations and process industries all over the world are facing the problem of boiler tube failure frequently. This affects the performance of the power plants leading to a huge amount of money loss. This study performs detailed efficiency testing and simulation of thermal flow inside an industrial boiler. The simulations were carried out using commercial available CFD software. The analysis of the temperature distribution for every location inside the domain is conducted by setting constant heat fluxes, and varying parameters such as mass flow rate of steam, steam inlet temperature and scale thickness. The results showed that the temperature distribution at the tube wall decreases with increase in mass flow rate of steam; decrease in steam inlet temperature; and increase in scale thickness.
\end{abstract}

Keywords - Biomass boiler, CFD, Temperature profile, Mass flow rate.

\section{INTRODUCTION}

Boilers are commonly used in industries to burn fuel to generate process steam and electric power. Due to economic and environment demands engineers must continuously focus on improving the boiler efficiency and reducing emissions. Computer simulation can be employed to understand the thermal flow in the boiler and to solve operation problems with optimal solution. The simulation was conducted using a commercial CFD package for modeling heat and fluid flow and predict the performance of the boiler. The CFD helps engineers to optimize the operating conditions and also to improve the design of new boilers. The CFD predictions can explore the real phenomena which happen in places where experimental investigation is impossible or expensive. Performance parameters of a boiler like efficiency and evaporation ratio reduces with time, due to poor combustion, heat transfer fouling and poor operation and maintenance. Even for a new boiler reasons such as deterioration of fuel quality and water quality can result in poor performance of boiler. Efficiency testing helps us to find out how far the boiler efficiency drifts away from the best efficiency. Any observed abnormal deviations could therefore be investigated to pin point the problem area for necessary corrective action. Hence it is necessary to find out the current level of efficiency for performance evaluation. This is a pre-requisite for energy conservation action in industry.

The purpose of the performance test is to determine actual performance and efficiency of the boiler and compare it with design values or norms. It is an indicator for tracking day-to-day and season-to-season variations in boiler efficiency and energy efficiency improvements. A heat balance helps to identify avoidable and unavoidable heat losses. Boiler efficiency tests help us to find out the deviation of boiler efficiency from the best efficiency and problem area for corrective action can be targeted. The performance of boiler was carried out by way of calculating the efficiency of boiler by direct method and indirect method. To make the boiler more efficient, less emissive and less prone to tube rupture, it is important to understand the combustion and thermal flow behaviors inside the boiler. This study performs a detailed simulation of combustion and thermal flow behavior inside an industrial boiler.

\section{LITERATURE REVIEW}

Saripally et al. (2005) conducted a simulation of thermal flow in an industrial boiler using a CFD package. Computer simulation has been employed to understand the thermal flow in the boiler to resolve the operational problem and search for optimal solution. The combustion and thermal flow behaviour inside the boiler is studied to make the boiler more efficient, less emissive and less prone to tube rupture. The study performs a detailed simulation of combustion and thermal flow behaviour inside the industrial boiler. Due to excessive heating the rupture of super heater tubes may lead to boiler shutdown, increasing the expense incurred. The CFD analysis provided fluid velocity, pressure, temperature, and species concentration throughout the solution domain. During the analysis, the geometry of the system and boundary conditions such as inlet velocity and flow rate was changed to view their effect on thermal flow patterns or species concentration distribution.

Masoud et al. (2006) reported the reasons for tube damage in the superheater platen section of the 320MW Bisotoun power plant. A three dimensional modeling was performed using a computational fluid 
dynamics code in order to explore the reasons for the damage of superheater tubes that occurred in a series of elbows belonging to long tubes. The code had ability of simultaneous solving the continuity, the ReynoldsAveraged Navier-Stokes equations by employing the turbulence, combustion and radiation models. The main aim of the modeling was to find the reason for the tube rupture inside the boiler. The study largely focused on heat transfer to the boiler tubes and the temperature field inside the boiler by incorporating combustion models besides other transport phenomena calculations.

McKenty et al. (1999) successfully simulated several different types of industrial boilers and incinerators fired with different types of fuels. Comparisons were made with measurements taken at various outlets show good agreement with the predicted values. Wardle (2000) used ultrasonic Nondestructive Oxide Thickness Inspection System (NOTIS) to nondestructively assess a large number of tubes in a relatively short time. Prior to the development of this system, the only method was through the destructive removal of tube samples. Srikanth et al. (2003) analyzed the failures of boiler tubes due to fireside corrosion in a waste heat recovery boiler utilizing the exhaust gas of a gas turbine fired with high-speed diesel. It was reported that the high corrosion propensity and consequent failures in the low temperature sections of the boiler were found to be directly related to the formation of hydrated ferric sulfate in these regions. Romeo and Gareta (2006) presented the methodology of neural network design and application for a biomass boiler monitoring stating the advantages of neural network in these situations.

Chaudhuri (2006) showed that the failure takes place due to short-term overheating in the final superheater tubes. It is also reported that the un-failed re-heater tubes exhibit higher tensile properties than that of platen super-heater tubes. Ranjbar (2007) made analysis on the failure and shut down of boiler cold and hot reheater tubes by chemical analysis of sediments and metallographic examinations. It was concluded that the bad maintenance and feed water chemistry are the main causes of the failure, leading to various types of corrosion mechanisms. Rahman and Sukahar (2008) presented the application of finite element method (FEM) to analyze the tube temperature distribution in a water tube boiler. Two-dimensional (2-D) finite element models were developed and axi-symmetric triangular elements for the tube cross section area were employed. The results showed that the temperature distribution at the tube wall decreases with increased mass flow rate of steam and increased scale thickness.

Korytnyi et al. (2008) developed an engineering tool by which the combustion behaviour of coals in coal-fired utility boilers can be predicted. It was reported that computational fluid dynamic codes can successfully predict performance of full-scale pulverized-coal utility boilers of various types, provided that the model parameters required for the simulation are properly chosen and validated. Purbolaksono et al. (2009) presented investigation study on the failed re-heater tube by finite element modeling. One of the major contributions to the tube failure was the scale formation developed on internal surface of the boiler tubes which reduces the heat transfer rate across the tubes.

\section{PROBLEM SETUP AND MODELING}

The overall design of the boiler is shown in Figure 1. The model basically consist of steam drum, mud drum and boiler tubes. The boiler tubes and regions of flue gas/water flow is shown in the figure. The fuel is burned in the combustion chamber and the flue gas passes over the saturated and superheated tubes and finally exhausted through the chimney. Precise measurements inside the industrial boilers are difficult to obtain. The CFD modeling is a useful method to explore the real phenomena which happens in places where the experimental investigations are difficult or expensive. The use of CFD codes for modeling of combustion, heat and fluid flow helps to predict the performance of boilers among the scientific and industrial communities.

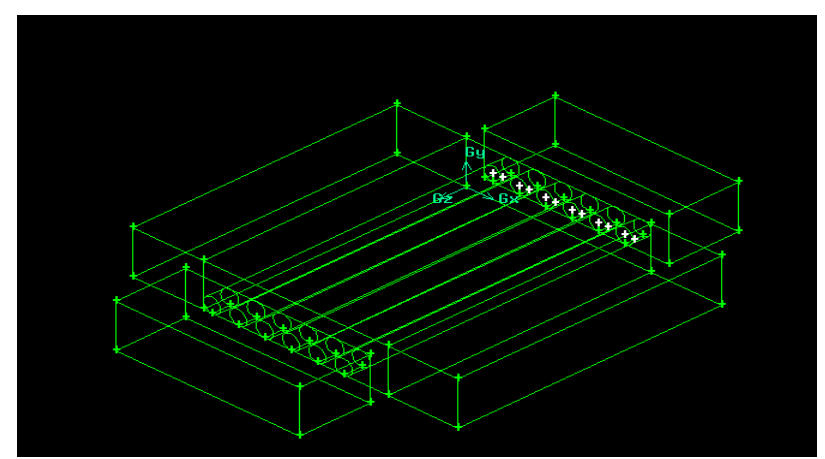

Figure 1 Model of studied boiler

A model was created for simulation using CFD technique for a biomass fired water tube boiler. The common causes of the metallurgical failure of the tubes in water tube boilers are the higher tube temperature attained than expected in the original design. Steam temperature is frequently measured in a boiler, but local 
tube temperature and temperature distribution are rarely measured and sometimes impossible due to varied temperature range caused by high load fluctuations and also due to steam side oxide scale growth during operation. However the remaining life span of the boiler tubes that is installed in a fossil fueled boiler can be predicted if the stress and average temperature of tubes, together with the way, tubes are thinned or scared as a result of erosion and corrosion process are known. In order to avoid the tube failure, detection of tube temperature distribution is necessary to take proper action.

Internal pressurized tubes are critical component in water tube boilers and steam superheater elements. Tubes in such application are vulnerable to temperature excursions and as a consequence, the material may enter the creep regime, and cause creep deformation leading to fracture. Therefore, boiler tubes in power plants have finite life because of prolonged exposure to high temperature, stress, aggressive environment and corrosive degradation.

A three dimensional CFD simulation was carried out in order to model the boiler in Palm Oil Mill, Oil Palm India Ltd, Kollam, India. A three dimensional model was developed and CFD code was used to resolve the flow of water and temperature distribution inside the tubes. The regions of the boiler such as air entrance channel and tubes were meshed with finer grids for precise calculation. The 3D domain was meshed with 0.2 million tetrahedral control volumes and is shown in Figure 2.

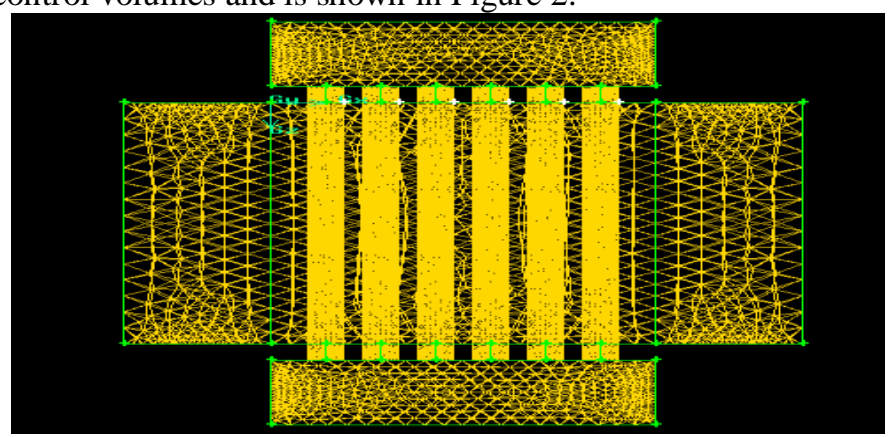

Figure 2 Model of studied boiler with mesh

\subsection{COMPUTATIONAL DOMAIN WITH BOUNDARY CONDITION}

\section{SIMULATION OF THERMAL FLOW}

\subsubsection{Boundary Condition}

The flow and thermal variables are defined by the following boundary conditions.

Fuel inlet... $0.694 \mathrm{~kg} / \mathrm{s}$

Air inlet. ... $4.9 \mathrm{~kg} / \mathrm{s}$

Pressure.

1 bar

Mass flow rate. $.0 .01 \mathrm{~kg} / \mathrm{s}$

The simulations were conducted in two different ways based on the tube arrangements. The model consists of tubes arranged in regular fashion and also in staggered fashion. In view of the complex flow field in the boiler this study selected the SST k- $\omega$ model due to its suitability and robustness for a wide range of wall bound and free shear flows.

The commercial CFD software employs a control volume based technique to convert the governing equations which are solved numerically using the implicit method. In the segregated formulation the governing equations are solved sequentially, as it is segregated from one another.

\subsubsection{Convergence}

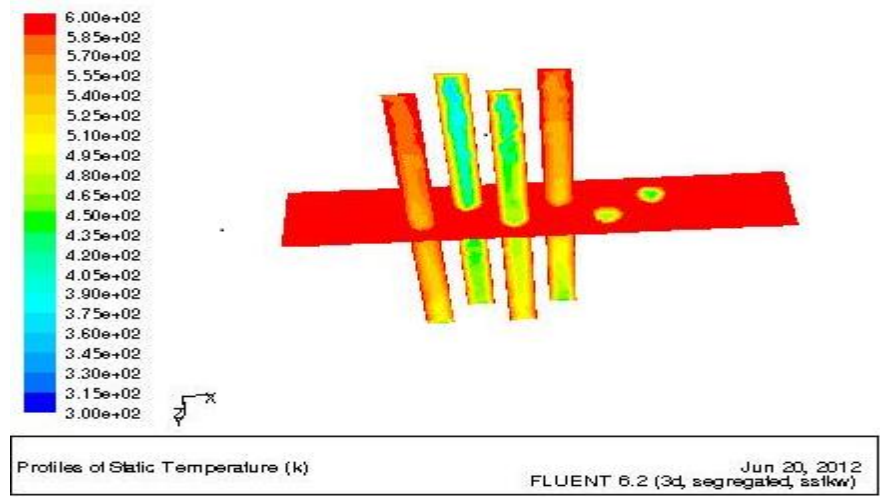

Figure 3 Profile of static temperature 
The solution convergence is obtained by monitoring the continuity, momentum, energy, turbulence and species equations separately. A convergence criterion of $10^{-4}$ is used for mass conservation and $10^{-6}$ for energy conservation. Figure 3 shows the profile of temperature distribution of water inside the tube. The temperature of the flue gas is $580 \mathrm{~K}$ and heat transfer takes place to the water inside the tubes. The temperature of the water inside the tube reaches approximately $495 \mathrm{~K}$ in the first tube. As the axial distance along the boiler increases the heat transfer rate decreases and is clear from the water temperature in the successive tubes as shown in figure. The temperature distribution in the boiler tube is affected by many variables such as mass flow rate of steam, steam temperature, feed water temperature and pressure. Therefore, effect of these variables is also considered by running a limited number of simulations.

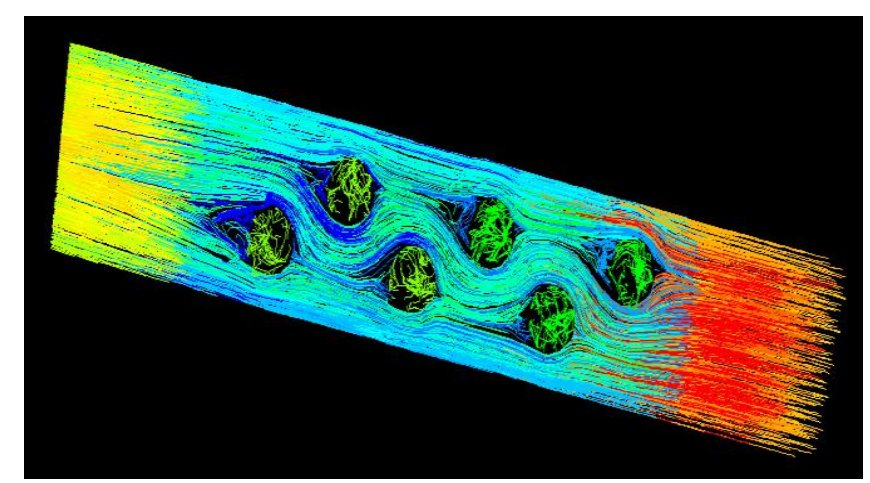

Figure 4 Profile of water flow inside the tube

\subsection{Performance Analysis}

\section{RESULT AND DISCUSSION}

Renewable energy sources are essential path towards sustainable development and carbon dioxide emission reduction. Therefore intense research is carried out in order to take advantage of biomass potential. Biomass characterization has been analyzed in detail, based on the comprehensive studies of biomass combustion behavior.

Performance of the boiler like efficiency and evaporation ratio reduces with time due to poor combustion, heat transfer fouling, poor operation and maintenance. Deterioration of fuel quality and water quality also leads to poor performance of the boiler. Efficiency testing helps us to find out how far the boiler efficiency drifts away from the best efficiency.

In order to analyse the performance of the biomass fired boiler, the work was carried out in a Palm Oil Mill. The boiler in Palm Oil Mill is used for processing palm seed and generating 0.5 MW power. Periodic efficiency testing is an important part of maintaining any boiler plant, as a small drop in efficiency represents a large amount of energy loss especially, where boiler has been operating for long periods of time without being tested. In such boilers, the efficiency has been found to fall by five or ten percent. Efficiency testing is the first step in estimating the benefit of potential boiler improvements. The improvements can be accomplished by adding an economizer or an air fuel control system in the circuit.

The thermal analysis of heat losses from boiler was presented in detail based on direct and indirect method. The second method is based on ASME standards where, the first six heat losses were considered. The fiber and shell contains low ash content and therefore heat loss from the source is not critical. For the heat loss due to radiation and convection, maximum of $0.5 \%$ of heat loss are taken into account. The main reason for not considering the last two heat losses in the above standards are because of unavailability of many practical data. The heat loss due to ash has to be taken as another topic of research.

The proximate and ultimate analysis of fuel showed that hydrogen and sulphur levels are quite low, resulting in relatively low $\mathrm{SO}_{\mathrm{x}}$ and $\mathrm{NO}_{\mathrm{x}}$ emissions. Moisture content is the key factor for determining the net energy content of biomass material. Dry biomass has a greater heating value as it uses little of its energy to evaporate any moisture.

From the boiler thermal analysis it was observed that the heat loss due to dry flue gases is the most dominant heat loss. For very high fiber content the heat loss due to moisture in the fuel must be taken into consideration. The heat loss due to incomplete combustion was found highly affected by the variation in excess air, but not too much affected by the ratio of fiber to shell.

The flue gas analysis of $\mathrm{CO}_{2}$ and $\mathrm{CO}$ can be determined by a portable flue gas analyser. By reducing the excess air the $\mathrm{CO}_{2}$ and $\mathrm{CO}$ level can be reduced and there by increasing the efficiency.

Fouling and slagging are some difficulties encountered while using biomass fuel in boilers. Biomass characterization has been analysed in detail and a comprehensive study of biomass combustion behavior has been conducted. The consequences of fouling include a reduction in boiler and power plant efficiencies. The 
boiler in the above industry considered does not have an economizer which also contributes for the reduction in efficiency. The actual data taken from the boiler was also below the design value.

\subsection{Temperature Distribution Due to Different Mass flow rate}

Figure 4 shows flow distribution of water and flue gas in the boiler tubes and surroundings respectively. The effect of the existence of scale to the temperature distribution in the boiler tube is compared with surface without scale. The minimum temperature is found to be $460 \mathrm{~K}$ at the inner tubes and maximum is $600 \mathrm{~K}$ at the outer surface of the tube wall for a of mass flow rate of $0.01 \mathrm{~kg} / \mathrm{s}$.

It is evident that the mass flow rate strongly influences the temperature distribution of the water tube boiler. It is found that the increase of mass flow rate of steam through the boiler tube causes the decrease in temperature in the inner tube wall. This behavior occurs due to heat releasing from flue gas to steam is not proportional as the ability to absorb heat from flue gas for higher mass flow rate is faster. If mass flow rate of steam is increased, as a consequence of it, temperature of flue gas must be increased to make heat balance in equilibrium condition

\subsection{Temperature Distribution Due to Different Steam Inlet Temperature}

The steam inlet temperature affects the thermal efficiency of a thermal power plant. The higher steam inlet temperature increases thermal efficiency. In contrast, operating boiler with higher temperature has some disadvantages ( ie. to make steam inlet temperature higher, more time is required, and also strength of tube materials should be considered as higher temperature will degrade the strength of material and thermal conductivity). Higher operating temperature can also increase scale growth. Therefore it is required to conduct simulation on the effect of steam inlet temperature to the temperature distribution in the boiler tubes. Figure 5 shows the minimum temperature of $460 \mathrm{~K}$ at the inner tube and maximum temperature of $600 \mathrm{~K}$ at the outer surface of tube for an inlet flue gas temperature of $600 \mathrm{~K}$. Figure 6 shows the temperature distribution in the boiler tube for a flue gas inlet temperature of $400 \mathrm{~K}$ and the subsequent variation in temperature along the tubes.

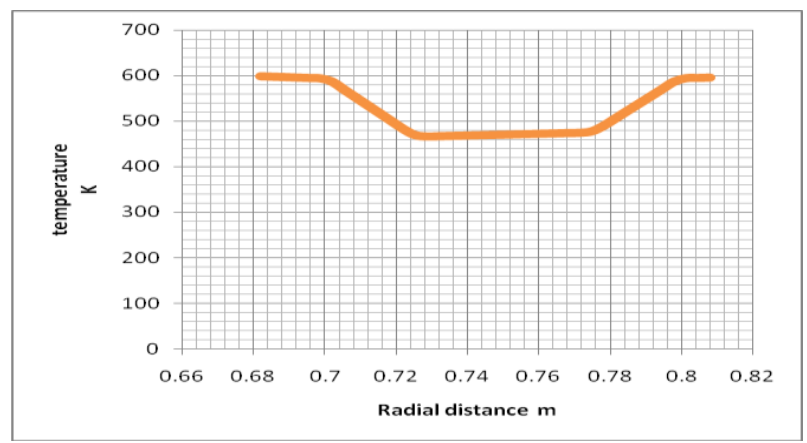

Figure 5 Temperature vs Axial distance

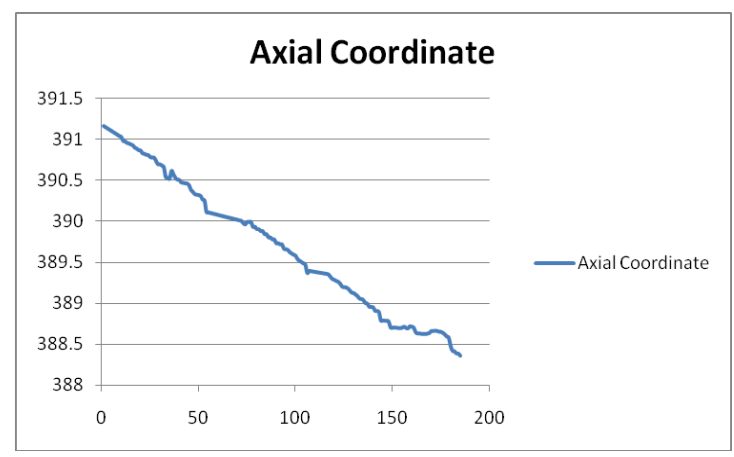

Figure 6 Temperature Vs Axial distance

It is found that different flue gas inlet temperature has implication on the temperature distribution at the boiler tube as all properties of tube material and fluid such as thermal conductivity, density, specific heat and dynamic viscosity are dependent on temperature.

\section{CONCLUSION}

Efficiency testing helps us to find out how far the boiler efficiency drifts away from the best efficiency. The performance analysis of boiler was carried out by direct and indirect method. Biomass characterization was analysed and a detailed study about biomass combustion behaviour was conducted. 
The analysis of performance of the biomass fired boiler was carried out in Palm Oil Mill and actual value was $82 \%$ (Indirect method) and $65 \%$ (Direct method) and found to deviate from the standard value due to losses. Periodic efficiency testing is an important part of the management of any boiler plant as a small drop in efficiency represents a large amount of energy loss, especially where boiler have operated for long periods of time without being tested. In the present study the efficiency of the boiler was found to drop by five to ten percent. The performance test of boiler in Palm Oil Mill was conducted after a long period of time, and hence a reduction of $10 \%$ of efficiency was noticed.

The proximate and ultimate analysis of fuel showed that Hydrogen and Sulphur levels are quite low, resulting in relatively low $\mathrm{SO}_{\mathrm{x}}$ and $\mathrm{NO}_{\mathrm{x}}$ emissions. Moisture content is the key factor determining the net energy content of biomass material. Dry biomass has a greater heating value as it uses little of its energy to evaporate any moisture. The flue gas analysis of $\mathrm{CO}_{2}$ and $\mathrm{O}_{2}$ can be determined by a portable flue gas analyzer. By reducing the excess air the $\mathrm{CO}_{2}$ and $\mathrm{O}_{2}$ level can be reduced and thereby efficiency can be increased. Fouling and slagging are some difficulties for the biomass fuel used in boilers. Biomass characterization has been analysed in detail and a comprehensive study of biomass combustion behavior was conducted. One of the major consequences of fouling is the reduction in boiler and power plant efficiencies.

Three dimensional CFD analysis has been conducted to determine the tube temperature distribution in the boiler. Commercially available CFD codes were used in this study. The analysis of temperature distribution for every location inside the domain is conducted by setting constant heat fluxes and varying parameters such as mass flow rate of steam, steam temperature, flue gas temperature, material properties of tube, scale thickness etc. From the result it is clear that the temperature distribution in the boiler tube is influenced by the above parameters. Although all parameters affect the temperature distribution in the boiler tubes, the existence of scale is very significant which decreases the temperature of tube wall. Hence to make heat balance in the equilibrium condition, temperature of the flue gas must be increased. The disadvantage of increasing temperature of flue gas is increasing scale growing and decreasing rupture strength of material. Therefore existence of scale must be eliminated.

The study shows that addition of an economizer in the system can considerably improve the performance of the boiler. During the course of this investigation two major areas were encountered for which further work is required. More research is required to minimize the effect of fouling once it has been detected. Applications of techniques like Neural Network that can predict a set of operational variables for determining the fouling state of the boiler. Also the prediction of $\mathrm{NO}_{\mathrm{x}}$ and $\mathrm{CO}_{\mathrm{x}}$ emission can be determined by incorporating species transport equations. The following recommendation may improve the efficiency of the studied boiler: (i) An addition of economiser in the system, (ii) Periodic soot blowing and (iii) Efficiency test in every three months.

\section{ACKNOWLEDGEMENT}

The authors wish to acknowledge Oil Palm India Ltd, Eroor, Anchal, Kollam, Kerala, India for their support and help given in the successful completion of this project work.

\section{Reference}

[1] Raja Saripally, Ting Wang and Benjamin Day. (2005) Simulation of combustion and thermal flow in an industrial boiler, Proceedings of $27^{\text {th }}$ Industrial Energy Technology Conference, New Orleans, Louisiana.

[2] Rahimi Masoud, Abbas Khoshhal and Syed Mehdi Shariati, (2006) CFD modeling of boiler tubes rupture. Journal of Applied Thermal Engineering, 26, 2192-2200.

[3] Mckenty. F., Gravel L., and Camarero.R. (1999) Numerical simulation of industrial boilers. Korean Journal of Chemical Engineering 16 (4) 482-488.

[4] T.J Wardle, (2000) Creep rupture assessment of super heater tubes using nondestructive oxide thickness measurements, International conference on life management and life extension of power plants.

[5] Srikanth S, Ravikumar B, Swapan K. Das, Gopalakrishna K., Nandakumar K., and Vijayan P. (2003) Analysis of failures in boiler tubes due to fireside corrosion in a waste heat recovery boiler -Engineering Failure Analysis., 10, 59-66

[6] Luis M.Romeo and Raquel Gareta, (2006). Neural network for evaluating boiler behaviour. Journal of Applied Thermal Engineering, 26, 1530-1536.

[7] Satyabrata Chaudhuri, (2006). Some aspects of metallurgical assessment of boiler tubes- Basic principles and case studies. Journal of Material Science and Engineering, A 432, 90-99

[8] Khalil Ranjbar, (2007). Failure analysis of boiler cold and hot reheater tubes. Journal of Engineering Failure Analysis, 14, 620625 .

[9] M.M.Rahman and Sukahar,(2008). Tube temperature distribution in water tube boiler - A parametric study by finite element method. International Conference on Construction and Building Technology, ICCBT-2008, 14, 157-170.

[10] Efim Korytnyi, Roman Saveliev, Miron Perelman and Boris Chudnovsky (2008) Computational fluid dynamic simulation of coal fired utility boilers: An emerging tool, Fuel, Elsevier.

[11] Purbolaksono, J., Khinani A, Ali A.A., Rashid A.Z., and Nordin.N.F (2009) Iterative technique and finite element simulation for supplemental condition monitoring of water-tube boiler. Journal of Simulation Modeling Practice and Theory, 17, 897-910. 